\title{
Analisis Manajemen Laboratorium Terpadu Mikroskopis Di Fakultas Kedokteran Universitas Cenderawasih Jayapura Papua (Studi Kasus)
}

\author{
Dais Iswanto ${ }^{1 *}$, Herlambangg Budi Mulyono² \\ 1*Dais Iswanto, Fakultas Kedokteran Universitas Cenderawasih Jayapura, 99351, \\ yabansay@gmail.com \\ ${ }^{2}$ Herlambang Budi Mulyono, Fakultas Kedokteran Universitas Cenderawasih, Jayapura, \\ 99351 : herlambangbm@yahoo.com \\ ${ }^{*}$ Corresponding author
}

Submisi: 17 April 2021; Penerimaan: 11 Juni 2021

\begin{abstract}
ABSTRAK
Keunggulan sebuah laboratorium pendidikan dapat direfleksikan dari kualitas dan profile manajemen yang dijalankannya. Tujuan penelitian ini adalah untuk mengetahui sistem manajemen yang dijalankan di laboratorium terpadu mikroskopis Fakultas Kedokteran Universitas Cenderawasih (FK Uncen) Jayapura, Papua. Metode penelitian menggunakan pendekatan metode kualitatif dan deskriptive. Hasil penelitian menunjukkan bahwa implementasi manajemen laboratorium tergolong kurang maksimal dan sebagian saja yang berjalan sesuai kaidah manajemen secara baku. Hal ini dibuktikan dengan hasil pengukuran indikator perencanaan (planing) sebesar 51,72\% mengindikasikan positif atau kategori "Baik" dan sebanyak 41,37 $\%$ masuk dalam kategori "Kurang". Sedangkan tiga komponen manajemen lainnya yang terdiri dari organizing, actuating dan controoling masing - masing indikator menunjukkan hasil sebesar 55,55 \% masuk dalam kategori "Baik" dan 44,44\% terbilang "Kurang". Temuan dapat digunakan sebagai bahan kajian penting dalam institusi untuk memperbaiki sistem manajemen laboratorium secara bertahap dan berkelanjutan agar diperoleh fungsi manajemen laboratorium yang ideal sesuai aturan yang semestinya.
\end{abstract}

Kata kunci: Laboratorium, manajemen, pendidikan, perencanaan, organisasi, kedokteran.

\section{PENDAHULUAN}

Kualitas manajemen laboratorium pendidikan yang unggul sangat dibutuhkan oleh Perguruan Tinggi untuk membantu menjalankan proses belajar mengajar secara efektif dan efesien. Untuk mendukung kondisi tersebut salah satu unsur penting yang perlu diperhatikan adalah kualitas manajemen laboratorium yang baik dan memadai. Temuan riset terdahulu menyatakan bahwa fungsi dan peranan sebuah laboratorium pendidikan memiliki sumbangan penting dalam meningkatkan kualitas pendidikan (Kartikasari, 2019). Di dalam aktivitas laboratorium sebagian besar adalah kegiatan praktikum, penelitian dan kegiatan akademik lainnya. Dampak positive yang diperoleh adalah dapat membangkitkan motivasi belajar, pengembangan keterampilan dasar para mahasiswa, dan berpotensi untuk meningkatkan interaksi sosial yang positif sesuai tujuan pembelajaran (Sari, Dayana, Ida, et al., 2018). Peningkatan mutu pendidikan dipengaruhi oleh beberapa faktor, salah satunya adalah laboratorium yang memiliki peran penting didalamnya. Aktivitas laboratorium, tenaga kependidikan dan tenaga pendidik yang profesional adalah faktor pendukung terwujudnya keberhasilan 
dunia pendidikan saat ini (Adriani, 2016). Penguatan dan perluasan fungsi laboratorium merupakan salah satu upaya penting untuk membangun sebuah universitas research. Dengan demikian laboratorium memiliki posisi dan peran yang memerlukan perhatian yang baik dan penanganan serius dalam lingkungan pendidikan tinggi (Utari, 2014). Mengingat fungsi penting laboratorium dalam pendidikan bukan sekedar tempat melakukan percobaan percobaan semata, namun sebagai wadah pembelajaran secara holistik serta tempat pembuktian berbagai teori ilmiah yang diperoleh dalam pembelajaran (Emda, 2017). Fungsi dan peran laboratorium pendidikan vital dalam lembaga pendidikan maka dibutuhkan tata kelola atau manjemen yang memadai dan profesional. Pendapat lain menyatakan bahwa untuk meningkatkan fungsi laboratorium secara profesional dibutuhkan manajemen laboratorium yang sesuai dengan kaidah manajemen baku (Lestari et al., 2017)

Kunci keberhasilan manajemen laboratorium pendidikan turut ditentukan oleh berbagai faktor seperti sumber daya manusia pendukung dari level bawah sampai pimpinan sehingga dapat mewujudkan iklim laboratorium yang ideal (Gunawan, 2019). Definisi umum manejemen laboratorium sendiri adalah segenap upaya yang ditempuh melalui proses perencanaan, organisasi, pengarahan dan pengawasan untuk mencapai tujuan organisasi yang didukung dengan seluruh sumber daya yang tersedia di laboratorium pendidikan (Indrawan et al., 2013). Salah satu fungsi manajemen laboratorium adalah menjamin penyelenggaraan pembelajaran dan praktikum bagi peserta didik secara efektif dan efesien (Sari, Dayana, \& Farida, 2018). Manajemen laboratorium yang baik akan menjamin pelaksanaan praktikum dengan benar dan lancar. Faktor faktor yang mendukung terciptanya manajemen laboratorium pendidikan yang baik diantaranya sumber daya manusia yang mumpuni, ketersediaan peralatan dan bahan memadai, dukungan pimpinan, keamanan, keberadaan tenaga teknis/nonteknis (Hamidah et al., 2013). Tata kelola laboratorium semakin berjalan normal jika unsur keamanan, kelengkapan sarana prasarana dan tenaga teknis non teknis senantiasa saling sinergis (Fiska et al., 2017).

Fakultas Kedokteran Universitas Cenderawasih (FK Uncen) sebagai salah satu institusi pendidikan kedokteran pertama di Tanah Papua memiliki beberapa laboratorium pendidikan klinik dan pre klinik yang mendukung proses belajar mengajar. FK Uncen berdiri sejak tanggal 16 September 2002 selama ini mengalami berbagai perubahan kurikulum, metode pembelajaran yang masih menganut mix model yakni model konvensional/ klasikal dan berbasis komptensi. Dalam kegiatan pembelajarannya selalu menyelenggarakan berbagai praktikum di tingkat pre klinik maupun klinik, meski terkadang share tenaga dan ruang dengan Fakultas lain seperti MIPA karena keterbatasan sumber daya. Berdasarkan pengamatan peneliti. FK Uncen memiliki laboratorium terpadu mikroskopis I dan II yang di ketua oleh seorang Kepala Laboratorium dengan peralatan dan bahan yang relatif lengkap. Namun ditinjau dari segi manajemen laboratorium diduga belum maksimal. Indikator yang dapat dilihat adalah belum menjalankan dokumen perencanaan secara maksimal, penyelenggaraan praktikum sering diluar perencanaan, sering dijumpai kegiatan praktikum tumpang tindih satu dengan yang lain, pengelolaan bahan dan 
peralatan pendukung masih tradisional/manual, sarana dan prasarana mendasar dalam laboratorium seperti pembuangan limbah belum ada, ketersediaan air bersih minim sekali, keadaan water closed kurang standart, belum memilik blower ruangan, jumlah tenaga laboran dan ruangan terbatas serta berbagai pendukung lainnya belum maksimal. Selain itu secara organisasi dan pengawasan dari kepala laboratorium belum dapat dilakukan secara optimal karena berbagai faktor seperti dokumen program dan belum memiliki peta manajemen yang jelas. Berdasarkan fakta tersebut peneliti ingin melakukan kajian tentang manajemen laboratorium terpadu mikroskopis di Fakultas Kedokteran Universitas Cenderawasih Jayapura Papua. Temuan penelitian ini diharapkan dapat digunakan sebagai landasan perbaikan manajemen laboratorium di masa yang akan datang agar pengelolaan laboratorium semakin baik, profesional sehingga dapat memberikan pelayanan pendidikan atau riset dosen dan mahasiswa secara maksimal.

\section{METODE PENELITIAN}

\section{Waktu dan tempat}

Penelitian dilakukan di laboratorium mikroskopis terpadu I di Fakultas Kedokteran Universitas Cenderawasih Jayapura, Papua. Waktu penelitian dimulai pada bulan Juli sampai september Tahun 2020.

\section{Metode penelitian}

Penelitian dilakukan dengan pendekatan kualitatif menggunakan analisa deskriptif. Data yang diperoleh dari seluruh komponen laboratorium yang terdiri dari kalab (kepala Laboratorium) Kaprodi (kepala prog.studi ) dan Pegawai Pranata Laboratorium Pendidikan (PLP). Teknik pengumpulan data melalui observasi, wawancara dan dokumentasi serta Observasi. Observasi dilakukan khusus terhadap 4 unsur manajemen laboratorium meliputi aspek Planing, Organizing, Actuacting,dan Controlling ( $P O A C$ ) dituangkan sebagai list pertanyaan yang terdiri dari 49 kriteria manajemen.

\section{Analisis data}

Data yang diperoleh selanjutnya dikelompokkan berdasarkan jenis dan fungsinya dalam tabulasi program excel dan dilakukan analisis statistik deskriptif menggunakan program SPSS V.25.

\section{HASIL DAN PEMBAHASAN}

\section{Hasil}

Keberhasilan tata kelola laboratorium pendidikan dapat terwujud jika persyaratan manajemen umum yang terdiri dari perencanaan, pengorganisasian, pengarahan dan kontroling terpenuhi sebagaimana mestinya. Temuan penelitian menunjukkan bahwa manajemen laboratorium terpadu di Fakultas Kedoktran Universitas Cenderawasih mendapatkan hasil sebagai berikut.

Hasil wawancara dengan Kepala Laboratorium Terpadu Mikroskopis I FK Uncen menyatakan bahwa pada prinsipnya implementasi manjaman laboratorium sudah dilakukan sesuai kemampuan dan kondisi saat ini. Bukti manajemen laboratorium ditunjukkan dengan perencanaan pengadaan, penganggaran, komunikasi verbal dengan petugas laboatorium dan rapatrapat mengenai pengelolaan laboratorium terutama praktikum, meskipun masih banyak kekurangan di sana sini. Diakui kondisi tersebut jauh dari ideal karena sumberdaya manusia terbatas, jumlah ruangan praktikum dan mekanisme pengadaan bahan bahan sering terlamabat. Hal ini membuat tantangan tersendiri bagi kami sehingga masih butuh banyak inovasi bahkan 
terobosan tertentu guna menjagastabilitas dan kelangsungan penyelenggaran kegiatan praktikum, penelitian maupun kegiatan akademik lainnya. Meskipun semua serba terbatas dan sulit paa intinya pembelajaran dan praktikum tetap harus jalan dengan keadaan tersebut.

\section{Berdasarkan}

wawancara

beberapa Pranata Laboratorium Pendidikan atau PLP Ahli muda dan terampil yang bertugas selama ini dapat dirangkum bahwa iklim kerja dan penyelenggaraan manajemen laboratorium cukup memprihatinkan. Hal ini dilihat dari sumber daya manusia, laboran, sarana penunjang, tenaga teknis sangat kurang dalam melayani sekitar 12 mata kuliah (laboratorium) yang berjalan di level pre klinik. Sedangkan tenaga PLP hanya empat orang dengan 2 orang yang masih relatif baru. Kondisi tersebut memaksa PLP untuk bekerja ekstra keras, tahan dengan berbagai tekanan dan penuh integritas. Selain itu, penyelenggaraan praktikum di luar waktu menjadi pilihan karena harus gantian dengan topik praktikum yang berbeda.

Dari penjelasan tersebut diketahui bahwa praktik manjemen laboratorium pendidikan di Fk Uncen sudah jalan namun belum maksilmal. Fungsi perencanaan dalam manajemen adalah bagaimana seorang pimpinan atau kepala suatu organisasi memiliki suatu tujuan tertentu dan cara cara khusus dalam mewujudkannya. Makna lain dapat diartikan sebagai upaya memperoleh sebuah tujuan dengan teknik tertentu. Perencanaan yang baik memiliki beberapa ciri berikut.

Keselarasan antara tujuan dan perencanan dalam organisasi, pimpinan tertinggi mampu berperan menjalan kan tugas dan fungsinya secara baik, koordinasi sesama komponen organisasi berjalan normal, terciptanya iklim organisasi yang solid, setiap pekerjaan yang ditugaskan kepada anggota dapat diselesaikan tepat waktu, semua komponen sumber daya manusia dalam organisasi dapat bekerja sama mengemban tugas masing masing.

Data penelitian diperoleh dari hasil cheklist manajemen dengan pilihan jawaban "ada" dan "tidak". Metode cheklist memiliki kelebihan praktis, terstandart dan mudah dalam memberikan penilainnya. Cara melakukan penilaian hasil cheklist dengan memberi bobot setiap jawaban untuk diberikan kuantifikasi sehingga diperoleh skor dalam bentuk persentase untuk dijadikan dasar kesimpulan penilaian. Hasil presentase yang diperoleh dari hasil perhitungan dikategorikan menjadi dua kelompok yaitu "baik" jika skor mencapai > 75\% dan dinyatakan "kurang" jika skor $<50 \%$ (Handoko, 1996). Cheklist komponen perencanaan manajemen laboratorium terdiri dari 29 indikator pernyataan yang menanyakan ketersediaan sarana prasarana, standart operasional prosedur, dokumen laboratrium, ketersediaan peralatan, bahan, kelngkapan pendukung laboratorium, penerangan, pembuangan limbah, keselatan kerja, bukti bukti perencanaan laboratorium yang relevan, kelengkapan serta kelayakan bangunan di laboratorium.

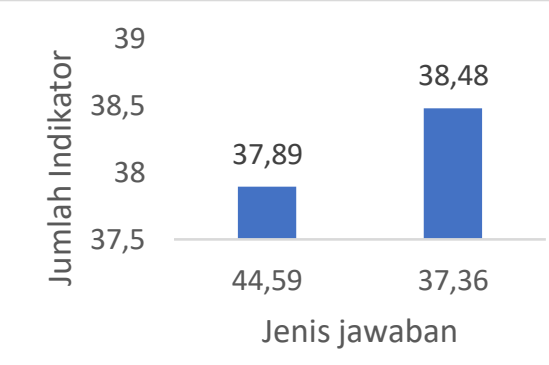

Gambar 1. perbandingan hasil jawaban aspek perencanaan laboratorium 
Hasil perhitungan cheklist komponen perencanaan diperoleh 15 indikator menjawab "ada/ ya" atau sebanyak (51,72 \%) dalam kategori "Baik" dan sisanya 12 indikator menjawab "tidak" (41,37 \%) sehingga termasuk dalam kategori "Kurang". Perbandingan jawaban komponen perencanan dalam manajemen laboratorium tampak pada gambar.1.

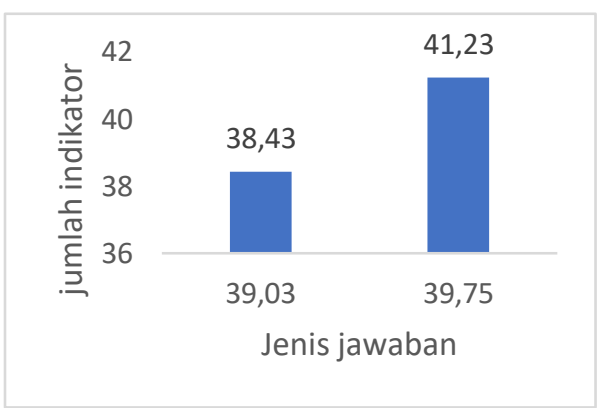

Gambar 2. perbandingan jumlah item positif dan negatif pengorganisasian

Indikator pengukuran organizing cheklist sebanyak 9 pernyataan. Dalam indikator tersebut memuat pernyataan tentang surat keputusan struktur organisasi, kegiatan seminar internal PLP, pembagian tugas dan fungsi yang jelas dan adil,sistem invertarisasi alat dan bahan, peraturan/tat tertib dan acuan kerja organisasi laboratorium. Hasil pengukuran menunjukkan jawaban positif sebanyak $5(55,55 \%)$ dan 4 item yang negatif $(44,44 \%)$ (Gambar.2). Salah satu unsur dalam manjemen adalah organizing, dalam praktiknya melakukan tugas pengaturan atau tata kelola tentang tanggung jawab bagi para pelaku organisasi. Di dalamnya terdapat sebuah integrasi dan sinergitas seluruh komponen oragnisasi dalam rangka mencapai tujuan berdasarkan perencanaan. Arti serupa dapat didefinisikan sebagai segala upaya dalam mewujudkan cita cita organisasi dengan mengerahkan seluruh sumber daya yang tetap berpedoman pada perencanaan organisasi. Produk dari unsur organizing adalah terbentuknya struktur organisasi.

Aspek ketiga dalam manajemen adalah actuating atau pelaksanaan diukur dengan 9 pernyatan yang terdiri dari sistem administrasi laboratorium, model dan meode penyimpanan alat dan bahan, ketepatan pelaksanaan praktikum, jenis penyelenggaraan praktikum kelompok atau mandiri, peran PLP dalam praktikum, dan peran dosen dalam praktikum. Hasil pengukuran indikator actuating/pelaksanaan diperoleh 5 item yang terdata positif $(55,55 \%)$ sedangkan 4 lainnya negatif $(44,44 \%)$ atau tidak memenuhi kriteria pelaksanaan yang telah ditanyakan (Gambar. 3). Dalam bidang manajemen unsur tesebut memiliki fungsi dominan dibanding unsur manajemen lainnya. Hal ini dikarenakan actuating bersifat lebih konkrit dalam praktik manajemen dan bersentuhan dengan sumber daya manusia dalam organisasi. Makna dari actuating adalah segala ikhtiar yang dipilih untuk dapat melakukan mobilitas semua komponen sumber daya manusia dalam rangka mewujudkan cita cita organisasi. Selain itu, terdapat hasrat bagi semua orang yang terlibat untuk memperoleh target organisasi.

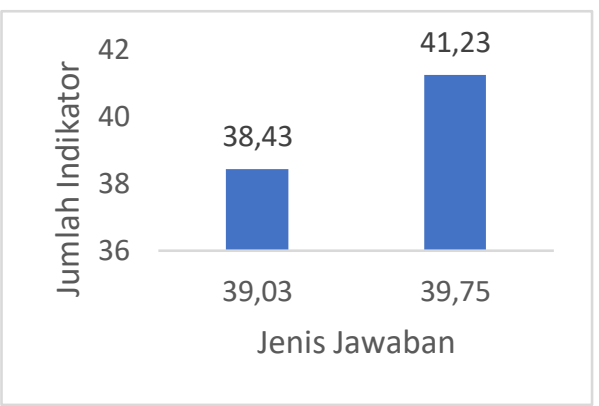

Gambar 3. jumlah item pelaksanaan manajemen lab terpadu

Unsur paling akhir dalam manajemen adalah controlling atau pengawasan. Komponen tersebut diukur menggunakan 9 item pernyataan meliputi tugas kepala laboratoriu (Kalab) 
dalam mengawasi penggunaan alat dan bahan, pengawasan Kalab terhadap administrasi, peran PLP dan dosen dalam pengawasan praktikum, pemantauan PLP terhadap alat dan bahan, diskusi PLP dan Kalab terkait berbagai hambatan penyelenggaraan praktikum, kepatuhan PLP untuk membuat laporan rutin, monitoring Kalab terhadap aktivitas laboratorium, monitoring perolehan kegiatan praktikum, dan kegiatan berkala Kalab dengan PLP untuk berbagai rapat internal membahas situasi laboratorium. Hasil engukuran diperoleh jumlah skor positif $5(55,55 \%)$ dan negatif $4(44,44$ $\%)$ (Gambar.4). Definisi dari controling adalah upaya terstruktur dan sistematis yang dilakukan oleh seorang pengawas/ pimpinan dalam rangka menilai adanya berbagai penyimpangan yang keluar dari perencanaan organisasi. Fungsi pengawasan dalam organisasi adalah langkah penting untuk upaya berbagai perbaikan agar kembali pada jalur perencanaan organisasi.

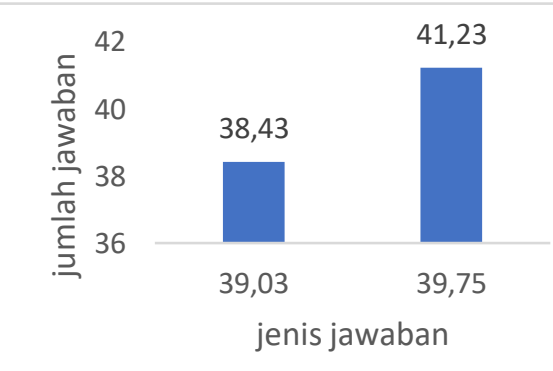

Gambar 4. Jumlah isian kontrolling manajemen lab terpadu mikroskopis

\section{Pembahasan}

Temuan

penelitian

mengungkapkan semua unsur manajemen laboratorium pendidikan di FK Uncen memiliki perbedaan hasil penilaian dari masing masing komponen manajemen secara umum. Hasil wawancara dari Kepala Laboratorium dan PLP membuktikan bahwa iklim kerja dan implementasi manajemen masih belum maksimal. Perntaan tersebut didukung oleh hasil perhitungan skor komponen perencanaan positif $(51,72 \%)$ memiliki nilai lebih tinggi dibandingkan komponen negatif $(41,37 \%)$ seperti pada gambar 1. Teori menjelaskan bahwa manajemen laboratorium pendidikan yang baik akan didukung oleh kecukupan sarana prasarana, sumber daya manusia yang kompeten, dukungan alam sekitar sebagai bahan belajar, sumber finansial yang adekuat, dan adanya dukungan dari pihak luar (Susilo, 2018). Keadaan tersebut memberi gambaran bahwa perlu adanya upaya perbaikan dan inovasi dalam mewujudkan manajemen laboratorium pendidikan di lingkungan FK Uncen untuk dapat lebih meningkatkan implementasi manejemen sesuai standart. Hakikat dari tujuan manajemen laboratorium pendidikan adalah menciptakan beberapa kondisi yang ideal seperti a). implementasi dan monitoring metode kerja laboratorium secara tepat guna, b). monitoring dan melakukan upaya berbagai perbaikan dari penyimpangan implementasi metode kerja laboratorium, c). selalu up to date dengan metode kerja organisasi sesuai kebutuhan zaman, d). selalu melakukan assesment kembali terhadap potensi potensi organisasi dan e). selalu kreatif dan produktif dalam rangka pengembangan laboratorium (Resmiaty, 2012).

Keadaan tersebut terjadi karena alasan sebagi berikut yaitu, FK Uncen belum melakukan praktik manajemen laboratorium yang baku, pimpinan laboratorium belum menerapkan kaidah manajerial yang memadai, iklim organisasi yang tidak sehat, sumber daya manusia secara umum masih rendah, penegakkan aturan yang lemah, kekuatan finansial tidak memadai, dan sistem organisasi termasuk budaya organisasi yang rendah. Alasan tersebut diperkuat oleh teori yang menyatakan 
bahwa dalam perencanaan pendidikan termasuk kegiatan di laboratorium, memiliki fungsi utama dalam tata kelola manajemen pendidikan, dan berperan sebagai pedoman penyelenggaraan manajemen pendidikan (Soemantri, 2014). Menurut Yusuf (2009) menyatakan bahwa peran perencanaan dalam pendidikan adalah kunci pokok dalam manjemen pendidikan. Dalam ruang lingkup perencanaan yang menjadi bagian tak terpisahkan dari suatu manajemen, praktik nyata pelaksanaannya berhubungan aspek manajemen lainnya seperti pengoragnisasian, pengawasan, program pembelajaran, pendekatan yang dipilih, sarana dan beban biaya yang dibutuhkan (Kasmawati, 2019).

Aspek organisasi (organizing) yang terdapat di laboratorium terpadu mikroskopis FK Uncen jayapura termasuk dalam kategori kurang, sembilan indikasi item positif/yang ada hanya $5(55,55 \%)$ dan siasanya 4 $(44,44 \%)$ terbilang negatif /tidak ada (Gambar.2). Hal tersebut menandakan bahwa secara organisasi dalam manajemen laboratorium sebagian besar masih membutuhkan penanganan dan upaya serius dalam mewujudkan manajemen yang baik dan berkelanjutan. Faktor organisasi hanya sebagian terpenuhi karena ketersediaan sumber daya manusia di lingkungan fakultas yang terbatas, rekrutmen pegawai laboratorium, dosen dan tenaga kependidikan belum maksimal, kompleksitas masalah laboratorium terkait dengan pengajaran yang belum terintegrasi dengan laboratorium dan iklim organisasi yang lemah. Kondisi demikian bertentangan dengan fungsi organizing dalam manajemen yang menekankan bahwa hakikat dari pengorganisasian adalah segala upaya untuk melakukan pengaturan seluruh sumber daya yang tersedia bukan sekedar personalia dalam rangka mencapai tujuan organisasi yang berpedoman pada perencanaan (Huda, 2016). Melihat fakta tersebut aspek pengorganisasian seharusnya mendapatkan perhatian penting guna menjalankan manejemen laboratorium yang lebih baik lagi. Ditegaskan dalam teori yang menyebutkan bahwa organizing memiliki peran dan fungsi dalam manajemen dengan cara melakukan sinergitas semua komponen pendukung untuk mewujudkan cita cita oragansasi (Ramli \& Warsidi, 2015).

Di tinjau dari aspek actuating atau implementasi pelaksanaan total dari 9 item indikator menunjukkan sebagian saja yakni hanya $5(55.55 \%)$ item positif dan $4(44,44 \%)$ termasuk negatif atau tidak terlaksana dengan baik (Gambar.3). Fakta tersebut merefleksikan bahwa sebagian besar implementasi manajemen belum berjalan dengan baik. Kendala implementasi manajemen laboratorium disebabkan oleh sinergitas antara dosen, kepala laboratorium, tenaga kependidikan dan tenaga laboratorium masih lemah. Kelemahan tersebut didukung juga oleh kualitas pelayanan, level kompetensi masing masing pihak yang tidak sama, ketersediaan alat dan bahan terbatas, perencanaan awal yang buruk dan rata rata di papua faktor stabilitas kampus yang tidak dapat diprediksi karena adanya demo dan pemalangan kampus yang mewajibkan kegiatan belajar mengajar libur demi keamanan bersama.Temuan ini sangat bertentangan dengan penelitian terdahulu yang menyatakan bahwa prinsip acuating dapat berjalan baik jika memenuhi kondisi sebagai berikut ; 1). Adanya partisipatif semua komponen terhadap implementasi perencanaan, 2). Personalia dibimbing secara benar dalam melakukan tugas tugasnya, 3). Memberikan semangat kepada 
karyawan, 4). Adanya komunikasi berkelanjutan secara baik, 5). Pimpinan mampu menunjukkan potensi diri bagi semua karyawannya, 6). Adanya reward yang memadai bagi karyawan (Awaluddin \& Hendra, 2018). Hampir semua keadaan tersebut belum pernah terjadi di lingkungan Fakultas Kedokteran Universitas Cenderawasih Jayapura.

Aspek kontroling dalam manajemen laboratorium diperoleh nilai atau skore 5 yang bisa dilakukan pengonrolan oleh pimpinan dan 4 item tidak dapat dikerjakan (Gambar.4). Sebagian kontrol tidak dapat dilakukan karena sistem dan aturan yang melekat dalam manajemn laboratorium belum baik. Selain itu kondisi tersebut dapat terjadi karena ketiga faktor lainnya seperti perencanaan, organisasi dan implementasi juga masih buruk. Sehinga tindakan kontroling akan berjalan seadanya dan tidak optimal.

Ramli (2016) menegaskan bahwa fungsi kontroling dalam manejemen laboratorium pendidikan adalah upaya assesment tehadap output yang diperoleh, dan usaha pembenaran terhadap hasil tersebut jika ditemukan perbedaan dari standart awal perencanaan. Fakta tersebut sering dianggap sebagai hambatan untuk peningkatan produktivitas, pada hal sejatinya fungsi pengawasan adalah hal mutlak dibutuhkan untuk menjamin pelayanan akademik yang dihasilkan benar benar sesuai target perencanaan. Bukti lapangan sering terjadi muncul berbagai penyimpangan dalam implementasi menjalankan manjemen yang baik. Pengawasan dapat berjalan semestinya ketika hubungan yang harmonis dalam organisasi dapat diciptakan (Ramli, 2016).

Limitasi penelitian ini adalah alat ukur yang digunakan hanya indikator manajemen laboratorium secara umum yang terdiri dari 49 item yang mewakili pernytaaan planing, organizing, actuating dan controlling dianggap belum melihat secara lengkap setiap detail perencanaan terhadap implementasi real yang dikerjakan di lapangan. Sehingga diperlukan kajian lanjutan yang fokus pada semua aspek perencanaan yang terdiri anggaran dan realisasinya, ketersediaan SOP, sinkronisasi penjadwalan dan kurikulum serta semua pendukung teknis implementasi perencanaan di laboratorium.

\section{PENUTUP}

\section{Kesimpulan}

Hasil pengukuran indikator perencanaan (planing) sebesar 51,72 \% mengindikasikan positif atau kategori "Baik" dan sebanyak 41,37\% masuk dalam kategori "Kurang". Sedangkan tiga komponen manajemen lainnya yang terdiri dari organizing, actuating dan controoling masing - masing indikator menunjukkan hasil sebesar 55,55 \% dalam kategori "Baik" dan 44,44\% terbilang "Kurang". Makna temuan adalah fungsi manajemen laboratorium terpadu mikroskopis di Fakultas Kedokteran FK Uncen masih kurang maksimal. Aspek paling baik diantara empat komponen manajemen adalah perencanaan, sedangkan aspek organisasi, actuating dan pengawasan hanya sebagian saja yang berjalan sesuai kaidah manajemen secara umum.

\section{Saran}

Berdasarkan temuan fakta tersebut maka sebaiknya seluruh komponen pimpinan dan jajarannya melakukan kajian kembali untuk merumuskan mengesahkan dan menerapkan manajemen laboratorium secara baik agar proses belajar mengajar dan kegiatan praktikum di tingkat pre klinik dapat semakin baik sesuai standart yang ditentukan. 


\section{DAFTAR PUSTAKA}

Adriani, N. (2016). ANALISIS MANAJEMEN LABORATORIUM KIMIA SMA NEGERI DI KOTA TANJUNGPINANG GUNA MENINGKATKAN KOMPETENSI GURU DAN PESERTA DIDIK Nina. Jurnal Zarah, Vol. 4, No. 1, 2016 (Halaman 1-8) ANALISIS, $4(1)$.

Awaluddin, \& Hendra. (2018). Fungsi Manajemen dalam Pengadaan Infrastruktur Masyarakat di desa watatu Kecamatan Banawa selatan Kabupaten Donggala. Antropologi Fisip Tadulako, 2(1), $1-12$.

Emda, A. (2017). LABORATORIUM SEBAGAI SARANA

PEMBELAJARAN KIMIA DALAM MENINGKATKAN

PENGETAHUAN DAN

KETRAMPILAN KERJA ILMIAH.

Lantanida Journal, 5(1).

Fiska, M., Hamidah, A., \& Budiarti, R. S. (2017). Analisis Pelaksanaan Manajemen Laboratorium Pada Pembelajaran Biologi Kelas XI SMA Negeri Kabupaten Muaro Jambi Mariza. Pendidikan Biologi FKIP Universitas Jambi, 2, 1-8.

Gunawan, I. (2019). Managemen Pengelolaan Alat dan Bahan di Laboratorium Mikrobiologi. Jurnal Pengelolaan Laboratorium Pendidikan, 1 (1) 2019, 19-25, eISSN: 2654-251X, 1(1), 19-25.

Hamidah, A., Sari, N., \& Budianingsih, R.

(2013). Manajemen Laboratorium Biologi. Sainmatika, 7(1), 1-10.

Huda, N. (2016). Fungsi Pengorganisasian dalam Manajemen. Media Karya Kesehatan, 7(2), 1-16.

Indrawan, I., Safita, R., Novalyan, D., Mahdayeni, M., Elsha, R. Y., Rochbani, I. T. N., Adiati, A., Jaya, E. P., Syafitri, R., Susanti, T., Maryani, \& Endarlita. (2013). Manaejemn Laboratorium Pendidikan. In CV.PENERBIT QIARA MEDIA (Vol. 53, Issue 9).
Kartikasari, S. N. (2019). PERAN LABORATORIUM SEBAGAI PUSAT RISET UNTUK MENINGKATKAN MUTU DARI LEMBAGA PENDIDIKAN PADA JURUSAN THP_FTP_UNEJ. 2(mei 2019), 17-28.

Kasmawati. (2019). Implementasi Perencanaan Pendidikan Dalam Lembaga Pendidikan Islam. JURNAL IDAARAH, VOL. III, NO. 1, JUNI 2019, III(36), 138-147.

Lestari, N. A., Jauhariah, M. N. R., \& Deta, U. A. (2017). Pelatihan Manajemen Laboratorium Untuk Pengelola Laboratorium Ipa Tingkat Sma Di Kabupaten Bojonegoro. Jurnal ABDI, 3(1), 17. https://doi.org/10.26740/ja.v3n1.p 17-21

Ramli, R. (2016). Pengawasan sebagai Fungsi Manajemen. Universitas Terbuka.

Ramli, R., \& Warsidi, A. (2015). modul Pengorganisasian sebagai Salah Satu Fungsi Manajemen. Universitas Terbuka.

Resmiaty, T. (2012). Aplikasi sistem informasi dan manajemen laboratorium. In kemenkes Republik Indonesia (Vol. 66).

Sari, S., Dayana, D., Ida, \& Farida. (2018). ANALISIS PROFIL MANAJEMEN LABORATORIUM DALAM PEMBELAJARAN KIMIA DI SMA WILAYAH SUMEDANG. 1(Juni), 73-82.

Soemantri, M. (2014). Perencanaan Pendidikan. In IPB Pess (Cetakan Pe, Vol. 7, Issue 2). IPB PRESS.

Susilo, B. (2018). Manajemen Laboratorium Dalam Upaya Mewujudkan Prestasi Belajar IPA. Media Manajemen Pendidikan, 1(2), 225. https://doi.org/10.30738/mmp.v1i2 .3256

Utari, R. (2014). PENGUATAN DAN PERLUASAN FUNGSI LABORATORIUM PADA RUMPUN ILMU SOSIAL DI PERGURUAN TINGGI. Dinamika Pendidikan, XXII(MEI 2017), 1626. 